\title{
Design of Functionally Graded Composites through Friction Stir Processing
}

B. V. Hima Sekhar SAI

DOI: 10.30464/jmee.2021.5.2.95

Cite this article as:

Sai B.V.H.S. Design of Functionally Graded Composites through Friction Stir Processing. Journal of Mechanical and Energy Engineering, Vol. 5(45), No. 2, 2021, pp. 95-102.

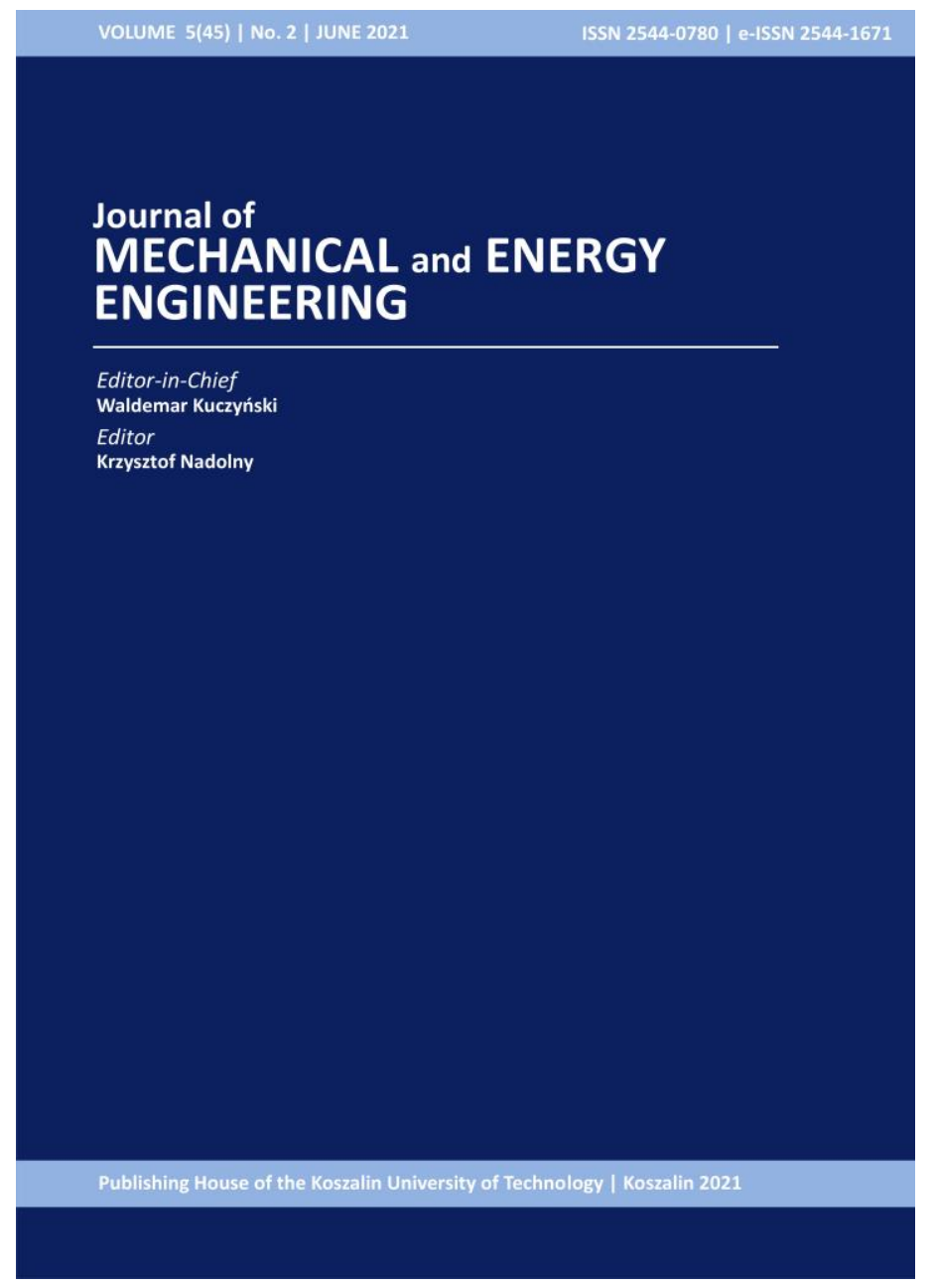

Journal of Mechanical and Energy

Engineering

Website: jmee.tu.koszalin.pl

ISSN (Print): 2544-0780

ISSN (Online): 2544-1671

Volume: 5(45)

Number: 2

Year: 2021

Pages: 95-102

Article Info:

Received 17 May 2021

Accepted 22 June 2021

\section{Open Access}

This article is distributed under the terms of the Creative Commons Attribution 4.0 (CC BY 4.0) International License (http://creativecommons.org/licenses/by/4.0/), which permits unrestricted use, distribution, and reproduction in any medium, provided you give appropriate credit to the original author(s) and the source, provide a link to the Creative Commons license, and indicate if changes were made. 


\title{
DESIGN OF FUNCTIONALLY GRADED COMPOSITES THROUGH FRICTION STIR PROCESSING
}

\author{
B. V. Hima Sekhar SAI ${ }^{*}$ \\ ${ }^{1 *}$ Department of Mechanical Engineering, Mahatma Gandhi Institute of Technology, Hyderabad, India \\ E-mail: bvhimasekharsai@gmail.com
}

(Received 17 May 2021, Accepted 22 June 2021)

\begin{abstract}
An Investigation was conducted to produce Aluminium based Functionally graded material (FGM) composites by Friction stir processing (FSP). A reinforcement strategy featuring the use of Alumina and $\mathrm{TiC}$ reinforcements was investigated, where holes were drilled in an Aluminium plate, filled with reinforcements and stirred using FSP. A mathematical model was formulated for the positioning of holes in such a manner that the composition of the reinforcements varies from maximum to minimum over a given length. Samples were subjected to various numbers of FSP passes from one to three with a 100\% overlap and its influence on particle distribution and homogeneity was studied using Scanning electron microscopy (SEM) at cross sections parallel to the tool traverse direction. A progressive gradient in hardness values was observed for the surface composites at all the passes.
\end{abstract}

Keywords: friction stir processing, functionally graded material, reinforcements, multi-pass FSP

\section{INTRODUCTION}

Functionally graded materials (FGM) are heterogeneous materials characterized by gradual variation in properties as the dimension varies. FGM have the ability to inhibit crack propagation that makes them useful in defense applications as penetration resistant materials used for armour plates and bullet-proof vests [1]. They can withstand very high thermal gradient making them suitable for use in structures and space plane body [2]. Other areas of application include Medicine, Energy, Cutting tool insert coating, Automobile engine components, Turbine blades, Heat Exchanger etc. Several methods like Powder Metallurgy, Centrifugal method, Chemical and Physical Vapour Deposition techniques, Solid free form fabrication (SFF) techniques namely, Laser cladding based method, Selective laser sintering, 3-D printing, Selective laser melting etc. are used in the fabrication of FGM [3]. Vapour deposition techniques can only be used for depositing thin surface coatings and they are not suitable for producing Bulk FGM [4]. Powder Metallurgy technique cannot produce a continuous grading, as it rather gives rise to a step wise structure. The centrifugal method offers continuous grading but it is limited to cylindrical shapes and the type of gradient that can be produced
[5]. SFF techniques have an advantage over other methods as they are capable of producing complex shapes and have greater design freedom since parts are made directly based on CAD data [6] but they are characterized by poor surface finish and they necessitate secondary finishing operations. One of the recent methods reported for fabricating FGM is Friction stir processing (FSP). Friction stir processing (FSP) is a solid state processing technique similar to friction stir welding, where a non consumable rotating tool with a probe and a shoulder is plunged into the surface and traversed along the path to be processed as shown in Figure 1, and bulk and surface composites can be fabricated. The temperature reached is below the melting point of the matrix material that avoids interfacial reactions with the reinforcement particles that is generally observed in liquid metallurgy techniques [7].

The heat generated due to the viscoplastic deformation softens the material and due to dynamic recrystallization, fine and equiaxed grains are produced in the stir zone. Dispersion of nanoreinforcements occurs in a uniform manner and control over the distribution is a critical and difficult task. Previous research on FSP for composite manufacturing was done by Mishra et al. [8] where 
$\mathrm{Al} / \mathrm{SiC}$ surface composites were fabricated, and it was concluded that $\mathrm{SiC}$ particles were well distributed in the Al matrix with good bonding between the matrix and the particles.

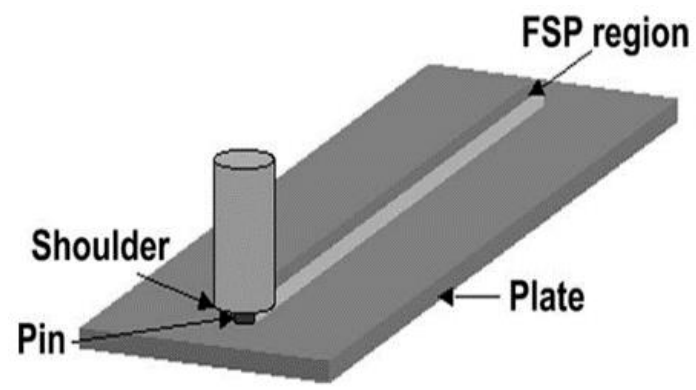

Fig. 1. Figure 1: Schematic of Friction Stir Processing Technique [8]

Mahmoud et al. [9] observed channel like defects in the composite surfaces produced by reinforcing $\mathrm{SiC}$ particles in AA1050 aluminium alloy by FSP and he studied the effect of tool geometry and processing parameters like tool rotation speed and travel speed. Miranda et al. [18] observed that pre depositing a uniform layer of hard particles prior to FSP with a non-consumable tool was a simple low time consuming method while the use of consumable rod drilled with holes, placed in different positions in the radial direction proved to be more effective in terms of particle recovery.

In the present study, an attempt was made to produce mechanical property gradients by FSP along the tool traverse direction (longitudinal direction) by drilling holes in an Aluminium plate and the positioning of holes was in accordance to a mathematical model intended to vary the composition of reinforcements from maximum to minimum. Followed by FSP, a characterization of the stirred zone in terms of the distribution of reinforcement particles, micro hardness and Youngs Modulus was carried out.

\section{EXPERIMENTAL PROCEDURE}

In the present study, commercial pure aluminium with a thickness of $6 \mathrm{~mm}$ and two different reinforcements, namely alumina nano powder sized $\sim 50 \mathrm{~nm}$ and $\mathrm{TiC}$ particles of size $44 \mu \mathrm{m}$ were used. The chemical composition of the substrate is shown in Table 1.

The tool pin was cylindrical and made of $\mathrm{H} 13$ tool steel with the diameter of $6.2 \mathrm{~mm}$, the length of $5.2 \mathrm{~mm}$ and the shoulder had a diameter of $27 \mathrm{~mm}$. The tool rotation was set to be $1000 \mathrm{rpm}$ and the traverse speed was $50 \mathrm{~mm} / \mathrm{min}$. To fill reinforcement particles, holes of diameter $1 \mathrm{~mm}$ were drilled to a depth of $5.2 \mathrm{~mm}$, over the length of $40 \mathrm{~mm}$ using a hole electric discharge machine, while the positioning of holes was done in accordance to the Mathematical Model stated below.

Tab. 1. Chemical composition of commercial pure aluminium (in wt \%)

\begin{tabular}{cccccc}
\hline $\mathrm{Al}$ & $\mathrm{Cu}$ & $\mathrm{Fe}$ & $\mathrm{Mn}$ & $\mathrm{Si}$ & $\mathrm{Zn}$ \\
\hline 98.95 & 0.005 & 0.457 & 0.014 & 0.564 & 0.006 \\
\hline
\end{tabular}

\section{MATHEMATICAL MODEL FOR THE POSITIONING OF HOLES}

The model was formulated to achieve a maximum composition $\left(C_{\max }\right)$ at the beginning, followed by a gradual decrease along the tool traverse direction and a minimum composition $\left(C_{\min }\right)$ at the end of FSP. In the present study, the composition of reinforcement particles was measured by considering a hole in a rectangular grid, as the ratio of the volume of the hole to the volume of the grid as shown in Figure 2, where $\Delta x_{i}$ is the length of the grid, $P_{d}$ is the diameter of the pin and $d$ is the diameter of the hole drilled.

$$
C_{i}=\frac{\pi \times d^{2} \times P_{l} \times 100}{4 \times \Delta x_{i} \times P_{d} \times P_{l}},
$$

where: $\mathrm{Ci}$ - percentage composition of reinforcement particles, $\mathrm{Pl}-$ length of the pin. If the composition is assumed to be varying in a linear fashion along the length $L$ parallel to the tool traverse direction then,

$$
C_{i}=b-a x_{i},
$$

where: $b=C \max , a=\frac{C_{\max }-C_{\min }}{L}, i-$ hole number and $x i$ is shown below in Figure 3 .

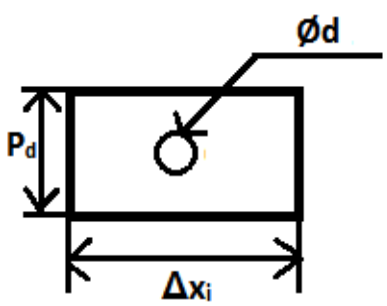

Fig. 2. Grid Size

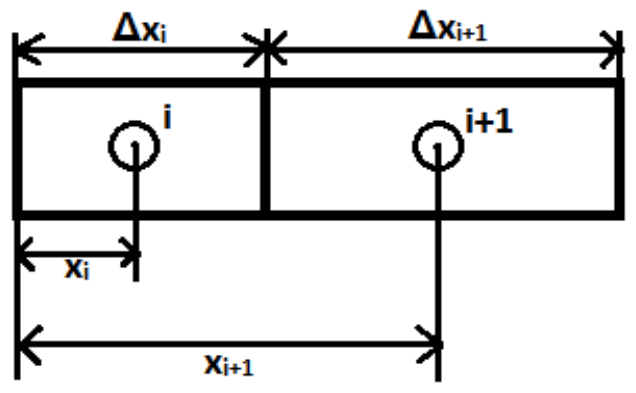

Fig. 3. Consecutive holes $i$ and $i+1$ 
Formula (1) can be written as:

$$
C_{i}=\frac{K}{\Delta x_{i}}
$$

where:

$$
K=\frac{\pi \times d^{2} \times 100}{4 \times P_{d}} .
$$

Equating (1) and (2) we get:

$$
\frac{K}{\Delta x_{i}}=C_{\max }-\left(a \times x_{i}\right) .
$$

From Figure 3:

$$
x_{i+1}-x_{i}=\frac{\Delta x_{i}}{2}+\frac{\Delta x_{i+1}}{2} .
$$

Similar to (2),

$$
C_{i+1}=b-a x_{i+1},
$$

solving (2) and (5) for $x_{i}+1$ and $x_{i}$ and substituting in (4) we get:

$$
C_{i}-C_{i+1}=\frac{a}{2} \times\left(\Delta x_{i}+\Delta x_{i+1}\right) .
$$

Similar to (3):

$$
C_{i}+1=\frac{K}{\Delta x_{i+1}} .
$$

Substituting (3) and (7) in (6) we get:

$$
\begin{gathered}
\left(\Delta x_{i} \times \Delta x_{i+1}^{2}\right)+\left(\Delta x_{i+1} \times\left(\Delta x_{i}^{2}-\frac{2 K}{a}\right)\right)+ \\
+\left(\Delta x_{i} \times \frac{2 K}{a}\right)=0 .
\end{gathered}
$$

Solving Equation (8) we get:

$$
\Delta x_{i+1}=\frac{-f \pm \sqrt{\left(f^{2}-\left(4 g \times \Delta x_{i}{ }^{2}\right)\right)}}{2 \times \Delta x_{i}},
$$

where:

$$
f=\left(\Delta x_{i}^{2}-\frac{2 K}{a}\right) ; g=\frac{2 K}{a} .
$$

These values are calculated until $\Delta x_{i+1}$ reaches the value of total calculated length $L i$.

$$
L_{i}=\sum x_{i+k}+\frac{\Delta x_{i+k}}{2},
$$

and the minimum composition is given by:

$$
C_{i}+k=\frac{\pi \times d^{2} \times 100}{4 \times \Delta x_{i+k} \times P_{d}} .
$$

Therefore, error in length = Actual length Calculated length $=L-L i$ and Error in composition $=$ Desired minimum composition - Calculated minimum composition $=C_{\text {min }}-C_{i}+k$.

From the Mathematical Model, considering $C_{\max }=8 \%, C_{\min }=2 \%$ (to avoid overlap of holes), $d=1 \mathrm{~mm}$ and $L=40 \mathrm{~mm}$, the lengths of the grids $\left(\Delta x_{i}\right)$ were primarily calculated followed by the values of percentage composition, shown in Table 2, and the linear variation in the composition along the length is shown in Figure 5 respectively. Hence, the grid size changes in such a way that the percentage composition of reinforcement particles changes accordingly, i.e. linearly.

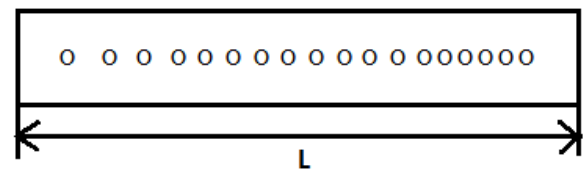

Fig. 4. Figure 4: Holes positioned as per the Mathematical Model

Tab. 2. Grid lengths and corresponding composition values for different holes

\begin{tabular}{ccc}
\hline Hole no. $(i)$ & $\Delta x_{i}, \mathrm{~mm}$ & Composition, $\%$ \\
\hline 1. & 1.583 & 8.000 \\
\hline 2. & 1.633 & 7.759 \\
\hline 3. & 1.687 & 7.510 \\
\hline 4. & 1.747 & 7.252 \\
\hline 5. & 1.813 & 6.985 \\
\hline 6. & 1.889 & 6.708 \\
\hline 7. & 1.974 & 6.418 \\
\hline 8. & 2.072 & 6.115 \\
\hline 9. & 2.186 & 5.795 \\
\hline 10. & 2.321 & 5.457 \\
\hline 11. & 2.485 & 5.097 \\
\hline 12. & 2.690 & 4.708 \\
\hline 13. & 2.956 & 4.285 \\
\hline 14. & 3.321 & 3.814 \\
\hline 15. & 3.868 & 3.275 \\
\hline 16. & 4.830 & 2.623 \\
\hline
\end{tabular}

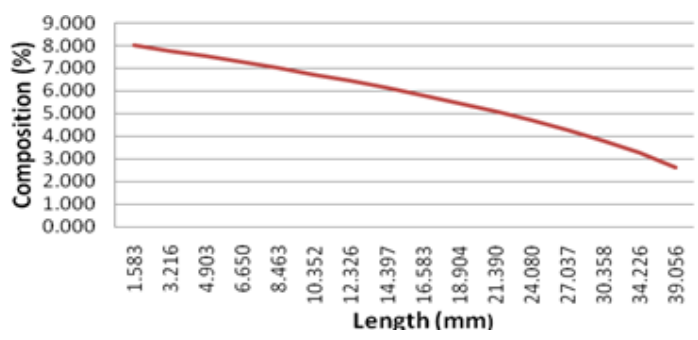

Fig. 5. Linear variation of composition with length

\section{PROCESS PREPARATION}

After drilling the holes that were positioned as per the mathematical model to achieve the maximum to minimum variation in the composition over a length of $40 \mathrm{~mm}$, the reinforcement particles were initially mixed with ethanol, filled completely in the holes and allowed to dry, to prevent ejection of reinforcement particles during FSP. The samples were subjected to various numbers of passes from one to three and were cut longitudinally at the center to measure Vickers hardness, with a load of $100 \mathrm{~g}$ at $0.5 \mathrm{~mm}, 1.5 \mathrm{~mm}$, $2.5 \mathrm{~mm}, 3.5 \mathrm{~mm}$ and $4.5 \mathrm{~mm}$ from the top of the surface composite layer. 


\section{RESULTS AND DISCUSSION}

\subsection{Surface appearance}

Visual inspection revealed defects such as cracks and voids which were observed in the first and second passes in the base metal, and reinforced composite surfaces were eliminated in the third pass as shown in Figures 6,7 and 8 respectively. In all the three cases, the top surface of the three pass FSP samples had a smooth surface finish with continuous rings. a)

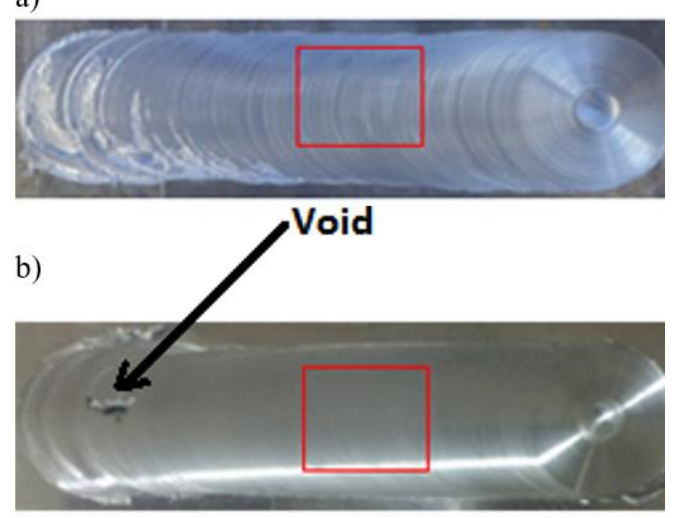

c)

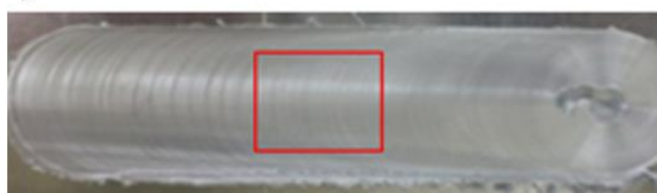

Fig. 6. Surface appearance of a) one pass b) two pass and c) three pass aluminium matrix

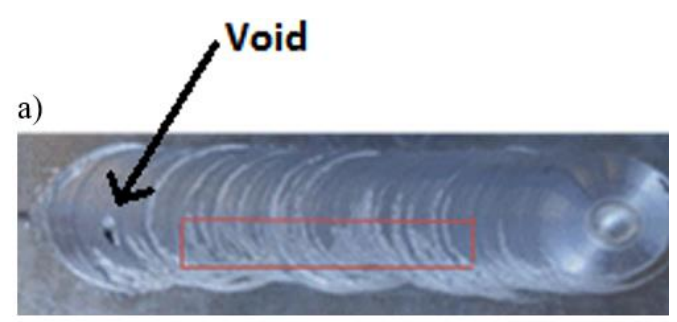

b)

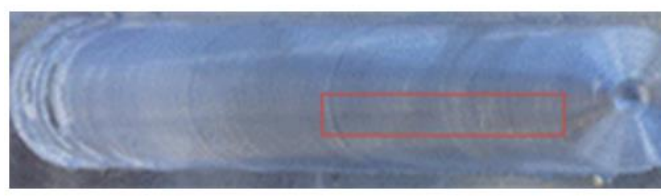

c)



Fig. 7. Surface appearance of $\mathrm{Al} / \mathrm{Al}_{2} \mathrm{O}_{3}$ surface composite layer produced by a) one pass b) two pass and c) three pass FSP

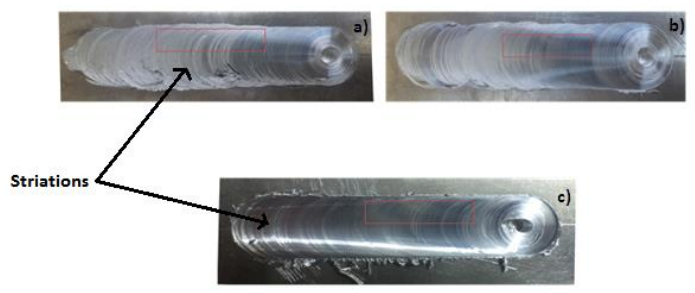

Fig. 8. Surface appearance of $\mathrm{Al} / \mathrm{TiC}$ surface composite layer produced by a) one pass b) two pass and c) three pass FSP

\subsection{Dispersion of Reinforcement particles}

The results of the mathematical model were supported by the SEM images shown in Figure 9, where a gradual decrease in the percentage composition of reinforcement particles from the maximum to the minimum in the tool traverse direction was observed, satisfying the requirements of a functionally graded material. The defects like cavities and voids which were observed at the cross sections of FGM in the longitudinal direction were related to the number of FSP passes. Cavities seen in the first pass were completely eliminated in the third pass as shown in Figures 10 and 11, indicating a good dispersion both of $\mathrm{Al}_{2} \mathrm{O}_{3}$ and $\mathrm{TiC}$ particles in the aluminium matrix.

It appears from the SEM images in Figure 12 that comminution [16] of $\mathrm{Al}_{2} \mathrm{O}_{3}$ reinforcement particles was observed in the second and third passes which looked like globules in the first pass showing the influence of the number of passes on the size of reinforcements in the zone stirred. The dark regions in the figure are $\mathrm{Al}_{2} \mathrm{O}_{3}$ particles, while the white particles are strengthening precipitates of the base material dispersed in the matrix as Zarghani et al. reported [17].

\subsection{Hardness measurement}

Figures 13 and 14 indicate the micro hardness readings in the longitudinal cross sections measured at $2.5 \mathrm{~mm}$ below the top surface for the cases of one, two and three pass friction stir processed specimens reinforced with $\mathrm{Al}_{2} \mathrm{O}_{3}$ and $\mathrm{TiC}$ particles respectively. In both figures, a progressive gradient in hardness values from $C_{\max }$ to $C_{\min }$ side can be observed. The scattering of hardness values is greater in the case of samples reinforced with $\mathrm{Al}_{2} \mathrm{O}_{3}$ nano particles in contrast to $\mathrm{TiC}$, where the fluctuations are significantly smaller indicating that the stirring action of the pin efficiently dispersed the TiC particles in a reasonably uniform manner compared to $\mathrm{Al}_{2} \mathrm{O}_{3}$ particles as shown in Figure 20. Figure 15 indicates that the hardness profiles in all the three cases are more than the hardness of the base material. The reason behind the increase in hardness for the case of $\mathrm{Al} / \mathrm{Al}_{2} \mathrm{O}_{3}$ functionally graded surface composite layer is because of the Orowan strengthening mechanism 
and due to the fine grain size of the Aluminium matrix.

\section{a)}

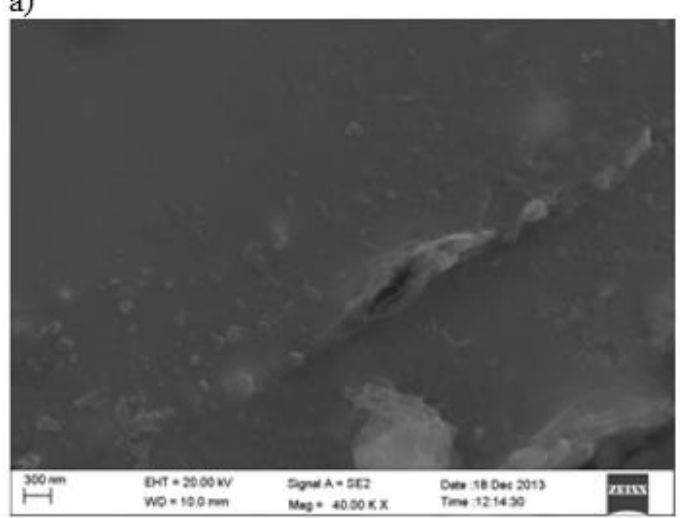

b)

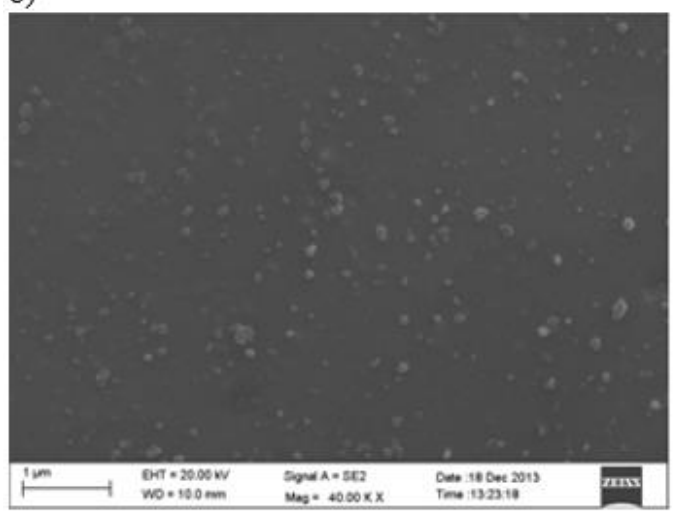

c)

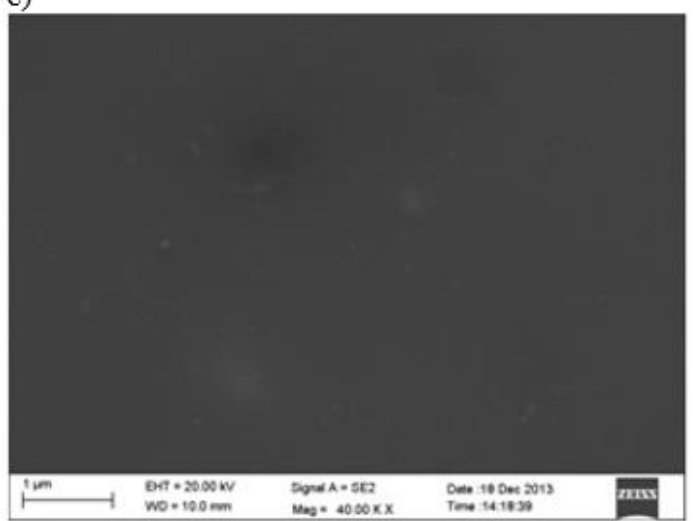

Fig. 9. SEM images of one pass $\mathrm{FSP} \mathrm{Al} / \mathrm{Al}_{2} \mathrm{O}_{3}$ surface nano composite layer at a) $0.5 \mathrm{~mm}$ b) $13.7 \mathrm{~mm}$ and c) $33.5 \mathrm{~mm}$ from the $\mathrm{C}_{\max }$ side a)

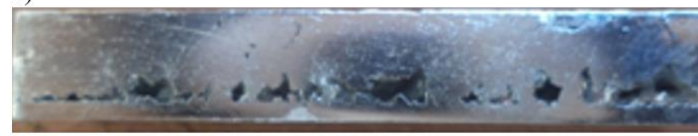

b)

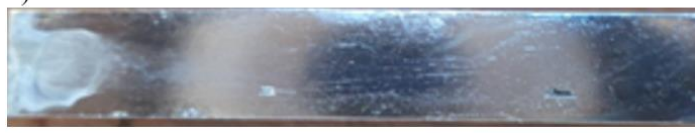

c)



Fig. 10. Longitudinal cross sections of a) one pass b) two pass and c) three pass $\mathrm{Al} / \mathrm{Al}_{2} \mathrm{O}_{3}$ FSP surface composites

a)

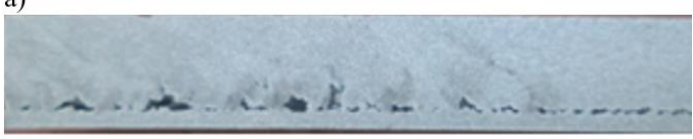

b)

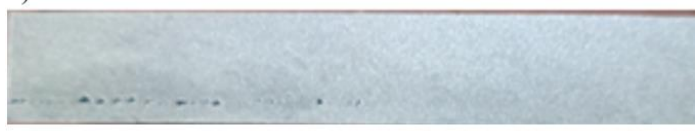

c)

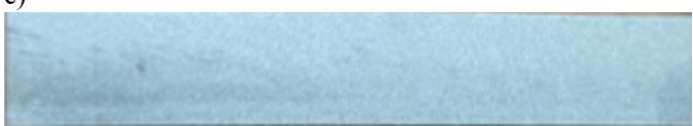

Fig. 11. Figure 11: Longitudinal cross sections of a) one pass b) two pass and c) three pass FSP Al/TiC surface composites

\section{CONCLUSIONS}

The present reinforcement strategy was found to be feasible in producing aluminium based functionally graded material composites by friction stir processing.

Defects such as cracks and voids reported in the first and second passes on the FSP surfaces as well as at the longitudinal cross sections were eliminated in the third pass.

A progressive gradient in hardness values was observed for one, two and three pass friction stir processed $\mathrm{Al} / \mathrm{Al} 2 \mathrm{O} 3$ and $\mathrm{Al} / \mathrm{TiC}$ surface composite layers. 
The size effect of the reinforcements was judged based on the hardness results which confirmed that, in spite of the high hardness of $\mathrm{TiC}$ particles compared to $\mathrm{Al} 2 \mathrm{O} 3$, it was $\mathrm{Al} 2 \mathrm{O} 3$ particles that contributed to the strengthening of the aluminium matrix through the Orowan mechanism due to the fact that $\mathrm{Al} 2 \mathrm{O} 3$ particles were nano sized and $\mathrm{TiC}$ particles were micro sized.

a)

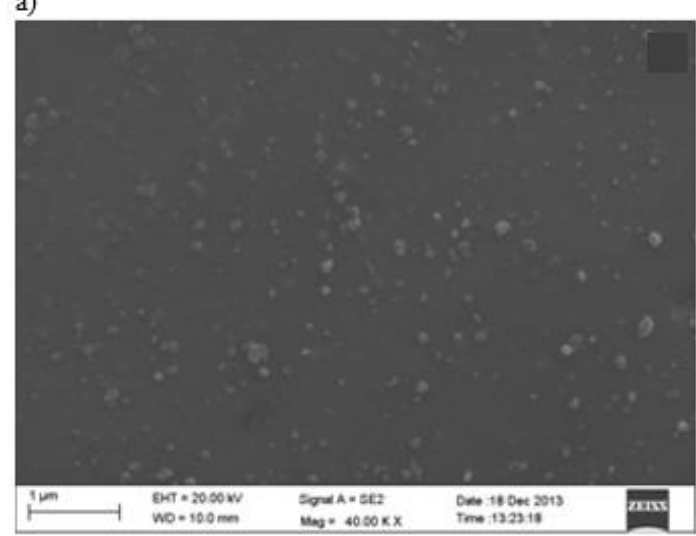

b)

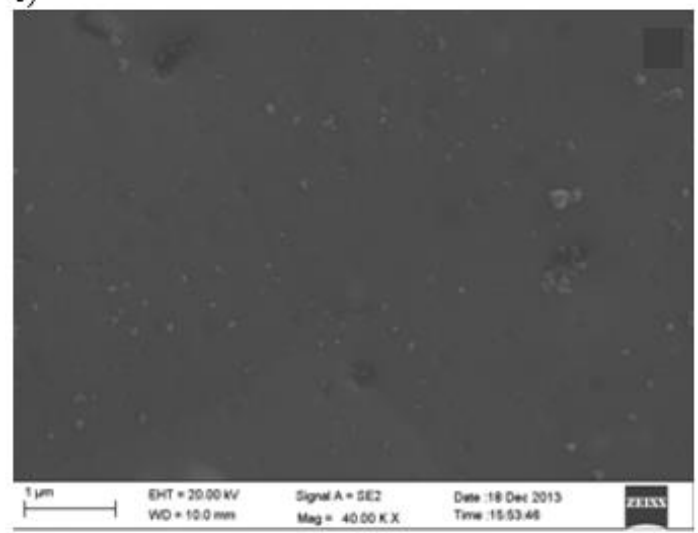

c)

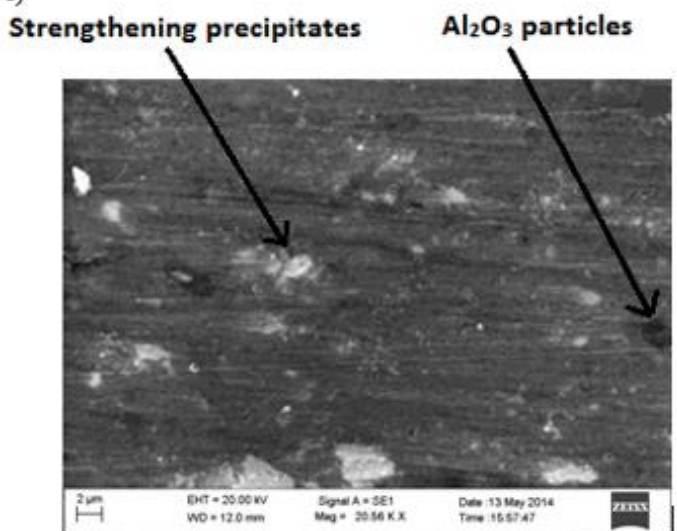

Fig. 12. SEM images of a) one pass b) two pass and c) three pass $\mathrm{FSP} \mathrm{Al} / \mathrm{Al}_{2} \mathrm{O}_{3}$ surface composites at $13.7 \mathrm{~mm}$ from $\mathrm{C}_{\max }$ side

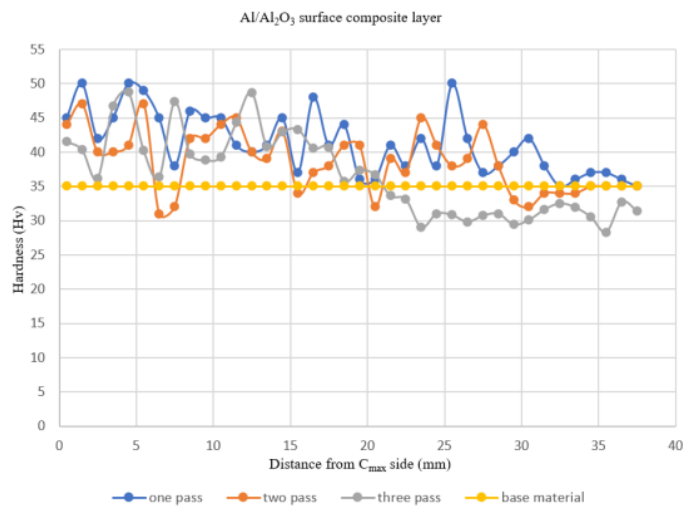

Fig. 13. Hardness profiles for one, two and three pass FSP $\mathrm{Al} / \mathrm{Al}_{2} \mathrm{O}_{3}$ surface composite layer

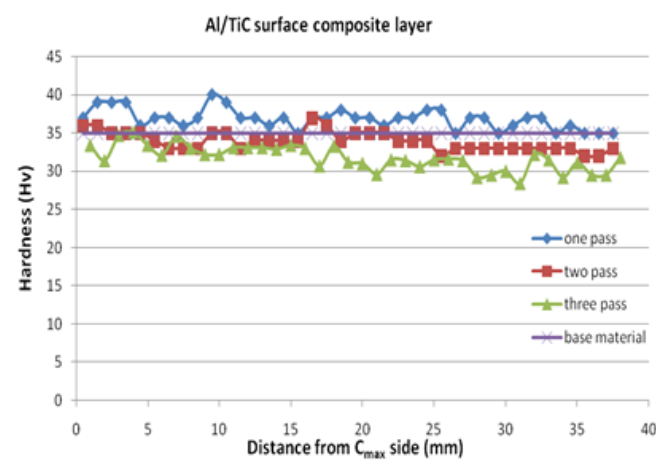

Fig. 14. Hardness profiles for one, two and three pass FSP $\mathrm{Al} / \mathrm{TiC}$ surface composite layer

\section{References}

1. Lu, L., Chekroun, M., Abraham, O., Maupin, V., Villain, G., 2011. Mechanical Properties estimation of functionally graded materials using surface waves recorded with a laser interferometer. NDT\&E International. 44, 169-177.

2. Marin, L., 2005. Numerical solution of the Cauchy problem for Steady-State heat transfer in two dimensional functionally graded materials. International Journal of Solids and Structures. 42, 4338-4351.

3. Mahamood, R.M., Akinlabi, E.T., Shukla, M., Pityana, S., 2012. Functionally Graded Material: An Overview. Proceedings of the World Congress on Engineering.

4. Groves, J.F., Wadley, H.N.G., 1997. Functionally graded materials synthesis via low vacuum directed vapor deposition. Composites Part B: Engineering. 28, 57-69.

5. Kieback, B., Neubrand, A., Riedel, H., 2003. Processing techniques for functionally graded materials. Materials Science and Engineering. 362, 81-105.

6. Lin, X., Yue, T.M., 2005. Phase formation and microstructure evolution in laser rapid forming of graded SS316L/Rene88 DT alloy. Materials Science and Engineering. 402, 294-306.

7. MA, Z.Y., 2008. Friction stir processing Technology: A review. Metallurgical and Materials Transactions. 39, 642-658.

8. Mishra, R.S., Ma, Z.Y., Charit, I., 2003. Friction stir processing: a novel technique for fabrication of surface composite. Materials Science and Engineering. A341, 307-310.

9. Mahmoud, E.R.I., Takahashi, M., Shibayanagi, T., Ikeuchi, K., 2009. Effect of Friction stir processing tool 
probe on fabrication of $\mathrm{SiC}$ particle reinforced composite on aluminium surface. Science and Technology of Welding and Joining. 14, 413-425.

10. Kumar, K., Kailas, S., 2008. The role of friction stir welding tool on material flow and weld formation. Material Science Engineering. 485, 367-374.

11. Gandra, J., Miranda, R., Vilaca, P., Velhinho, A., Pamies, T.J., 2011. Functionally graded materials produced by friction stir processing. Journal of Materials Processing Technology. 211, 1659-1668.

12. Zhang, Z., Chen, D.L., 2006. Consideration of Orowan strengthening effect in particulate-reinforced metal matrix nano composites: A model for predicting their yield strength. Scripta Materialia. 54, 1321-1326.

13. Reynolds, A.P., Duvall, F., 1999. Digital image correlation for determination of weld and base metal constitutive behavior. Welding Journal-Newyork. 78, 355-360.

14. Leitão, C., Galvão, I., Leal, R.M., Rodrigues, D.M., 2012. Determination of local constitutive properties of aluminium friction stir welds using digital image correlation. Materials and Design. 33, 69-74.

15. Mishra, R.S., Ma, Z.Y., 2005. Friction stir welding and processing. Materials Science and Engineering. 50, 1-78.

16. Thangarasu, A., Murugan, N., Dinaharan, I., Vijay, S.J., 2012. Microstructure and microhardness of AA1050/TiC surface composite fabricated using friction stir processing. Indian Academy of Sciences. 37, 579-586.

17. Zarghani, A.S., Bozorg, S.F.K., Hanzaki, A.Z., 2009. Microstructures and mechanical properties of $\mathrm{Al} / \mathrm{Al} 2 \mathrm{O} 3$ surface nano composite layer produced by friction stir processing. Materials Science and Engineering. 500, 84-91.

18. Miranda, R.M., Santos, T.G., Gandra, J., Lopes, N., Silva, R.J.C., 2013. Reinforcement strategies for producing functionally graded materials by friction stir processing in aluminium alloys. Journal of Materials Processing Technology. 213, 1609-1615.

\section{Biographical note}

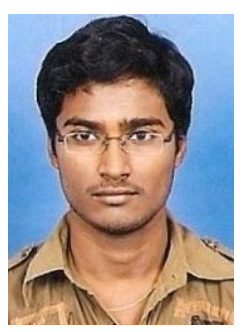

B.V.H.S. Sai received his M. Tech degree in Manufacturing from the Indian Institute of Technology, India, in 2014. 
